\title{
Khoảnh khắc SciMath cuối năm 2021
}

\author{
Vương Quân Hoàng \\ Trường ĐH Phenikaa \& VIASM
}

Hà Nội - Việt Nam

Jan. 1, 2022

Những giờ cuối cùng của 2021, năm Covid thứ 2 đầy khó khăn, chúng tôi vẫn còn chờ công việc khóa sổ năm hoàn tất. Đó là hoàn thành preprint trên trang của Viện Nghiên cứu cao cấp về Toán (VIASM). Chỉ khi báo cáo này có thể sẵn sàng để sử dụng, thì mới được coi là xong. Và cố gắng trong vài ngày cuối năm được bù đắp. Rất kịp thời, tới 31-12 đã có thể tải preprint [1] từ địa chi: https://viasm.edu.vn/Cms Data/Contents/viasm/Media/2021/Preprint 2129.pdf. Một trong những hình ảnh được trình bày trong [1] là lưới hợp tác của tác giả Cung Thế Anh:

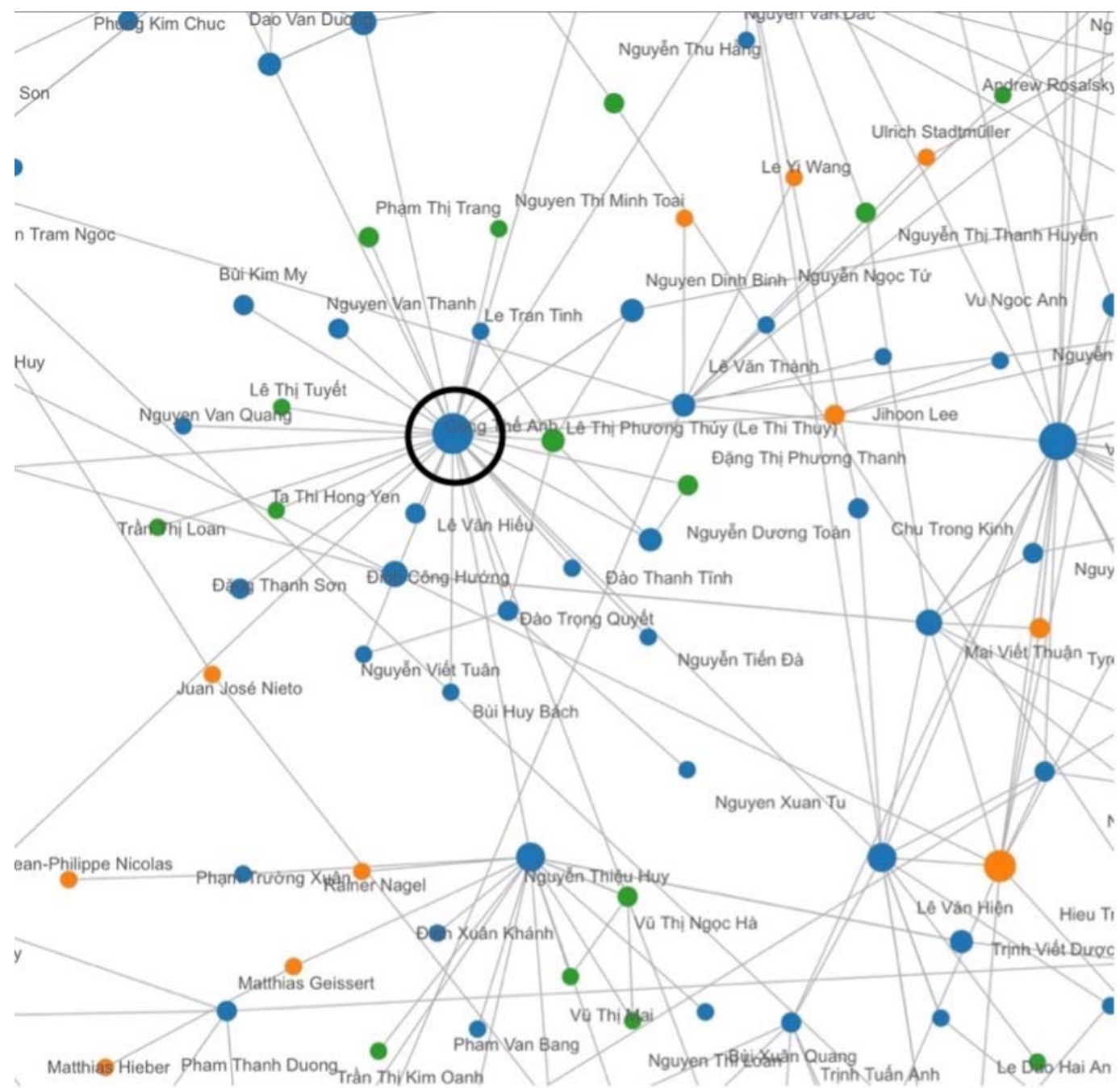


Đây là bản báo cáo thứ hai sử dụng CSDL SciMath, trong khuôn khổ dự án nghiên cứu của VIASM. Bản đầu tiên có thể tải từ arXiv: https://arxiv.org/abs/2011.09328, hoàn thành vào cuối 2020 [2]. Công việc này được triển khai đã qua vài năm, mặc đây mới chỉ là năm thứ hai có báo cáo xây dựng từ CSDL. Không một ai trong nhóm nghiên cứu, cũng như ban điều hành (bao gồm cả GS Ngô Bảo Châu), tính toán thời gian, công sức hay quan tâm tới lợi ích kinh tế, mà chỉ một lòng mong được thực hiện tâm nguyện. Tất cả mọi người đều hiểu rằng có được dữ liệu phục vụ việc tìm hiểu, dự báo xu hướng phát triển, và xác định các nhóm tiềm năng chính là một động lực để tạo nên hiệu quả đâu tư thời gian, công sức và tâm huyết của mọi người [3]. Chúng tôi chân thành tin rằng, tăng được hiệu quả sử dụng dữ liệu góp phần đáng kể nhằm giảm đi tương đối suất đầu tư cho hệ thống SciMath, cho dù đó là CSDL, giờ công nhập liệu, phần mềm phân tích, hay máy chủ.

Trước ngày GS Ngô Bảo Châu rời Hà Nội, quay lại kỳ giảng dạy ở ĐH Chicago, cuộc họp ngày 58-2021 có thể được xem như bước vào giai đoạn hoàn thiện và khai thác dữ liệu SciMath (trong hình). Có một vài hướng đã rất rõ ràng cho việc sử dụng dữ liệu, nhưng có những hướng lại cần việc quan sát, xới xáo và thăm dò trước khi xác định được đầu bài đáng công sức.

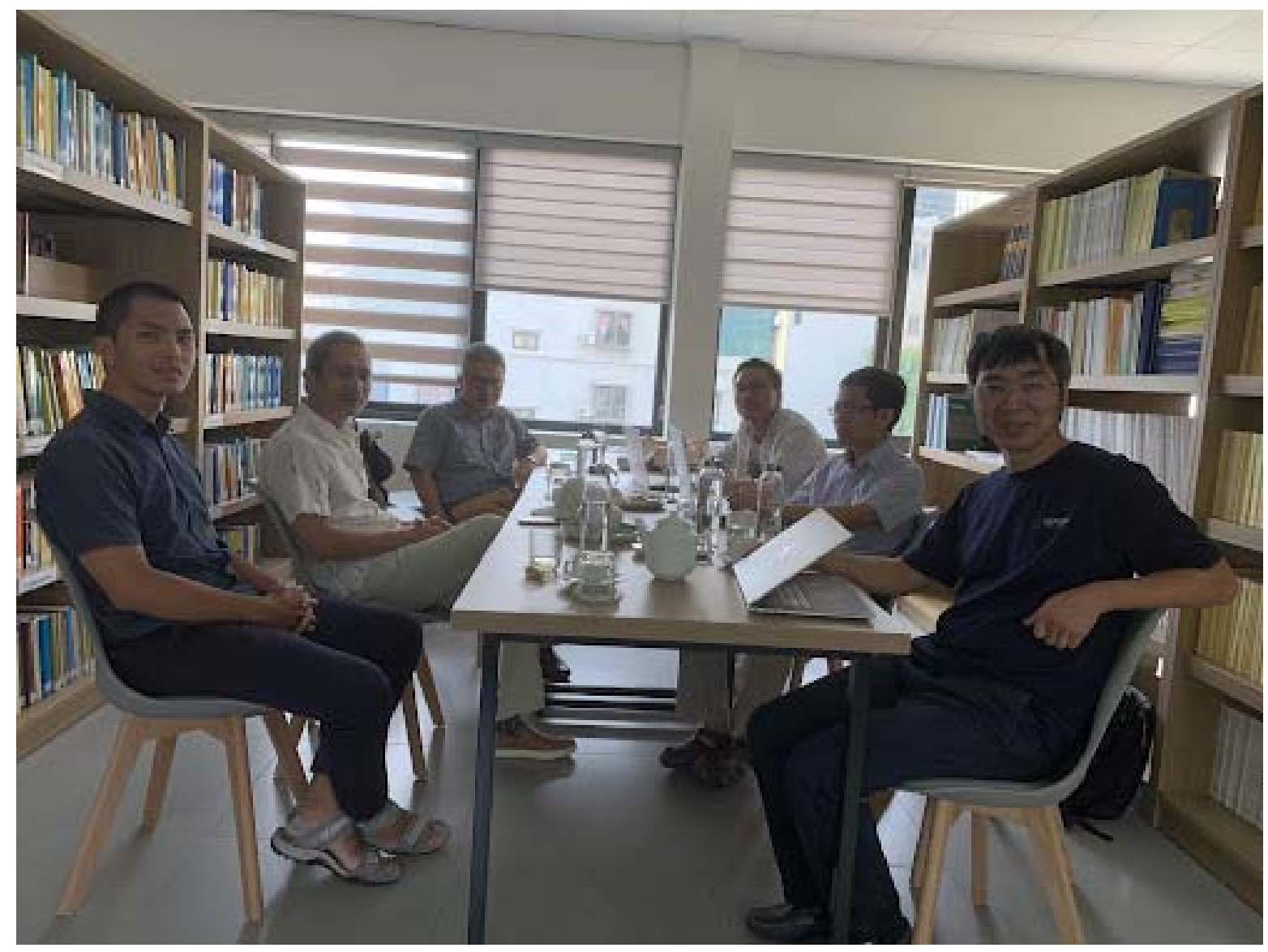


Về tổng thể, mọi việc có thể đánh giá đã diễn ra theo đúng kế hoạch và tuân thủ tinh thần đã được thống nhất từ tháng 8 , mặc dù thực tế có những lúc vấp phải nhiều thách thức do giãn cách xã hội vì dịch bệnh nghiêm trọng kéo dài.

Riêng đối với cá nhân tôi-sau những khó khăn mà đôi lúc tưởng chừng đã làm đội ngũ chùn bước-vượt lên và hoàn thành công việc mong mỏi chính là phần thưởng lớn nhất trong năm. Vì thễ, những giờ khắc cuối của năm 2021 được thấy việc còn lại khóa sổ khiến cho sự cố gắng suốt cả năm có ý nghĩa bội phần lớn hơn.

Xin tạm biệt 2021 và chào đón năm mới 2022!

\section{Tài liệu tham khảo:}

[1] Hoàng VQ, Phương LV, Huyên NTT, Toàn HM. (2021). Báo cáo biến động ngành Toán học năm 2010-2020. VIASM Preprints, No. ViAsM21.29. Available at: https://osf.io/6n3v2/

[2] Chau NB, Hoang VQ, Phuong LV, Hoa LT, Ha LM, Giang TTT, et al. (2020). The 80-year development of Vietnam mathematical research: Preliminary insights from the SciMath database on mathematicians, their works and their networks. arXiv Preprint, arXiv:2011.09328. Available at: https://arxiv.org/abs/2011.09328

[3] Vuong QH. (2018). The (ir)rational consideration of the cost of science in transition economies. Nature Human Behaviour, 2(1), 5. 